\title{
Serum level of Adrenomedullin in patients with primary knee osteoarthritis; relation to disease severity
}

\author{
Mervat I. Abd Elazeem', Aya B. S. Ahmed ${ }^{2}$, Rabab A. Mohamed ${ }^{3}$ and Enas A. Abdelaleem ${ }^{1 *}$ (i)
}

\begin{abstract}
Background: Adrenomedullin (AM) is a peptide which was suggested to be involved in the pathogenesis of osteoarthritis through its anti-inflammatory and anti-apoptotic effect. AM was found to be elevated in some inflammatory rheumatic diseases as rheumatoid arthritis and ankylosing spondylitis.

The current study was performed to measure serum Adrenomodullin (AM) concentrations in patients with primary knee osteoarthritis (KOA) and to assess association with severity of the disease. The study was performed on 50 patients with primary KOA diagnosed according to American College of Rheumatology (ACR) Revised Criteria for Early Diagnosis of Knee Osteoarthritis and 20 age- and sex-matched controls with no clinical features of KOA. The Kellgren and Lawrence (KL) classification was used to evaluate the disease severity of knee OA. Disease activity was assessed by The Western Ontario and McMaster Universities Arthritis Index (WOMAC). Blood samples had been collected from patients with OA and controls for assessing Adrenomodullin in patients' sera by ELISA.

Results: There were a significant increase in serum Adrenomedullin concentrations in KOA patients compared to controls (10.64 $\pm 19.2 \mathrm{ng} / \mathrm{ml}$ vs. $1.39 \pm 1.6 \mathrm{ng} / \mathrm{ml}$ in cases and controls respectively) ( $p$ value $=0.036)$. There was positive significant correlation of serum Adrenomedullin levels with $\mathrm{KL}$ grades $(r=0.608, p$ value $<0.001)$. OA patients with VAS score $>6$ have significantly higher serum Adrenomedullin levels than OA patients with VAS Score $<6$. No detected significant correlation between any of (patients' age, BMl, disease duration, tenderness score, and WOMAC score) with serum Adrenomedullin levels among studied OA cases ( $p$ values >0.05).
\end{abstract}

Conclusion: This study concluded that serum Adrenomedullin (AM) level is elevated in patients with KOA and is positively correlated with the severity of disease.

Keywords: Knee osteoarthritis (KOA), Adrenomedullin (AM), WOMAC, KL score

\section{Background}

Osteoarthritis $(\mathrm{OA})$ can be regarded as the most prevalent arthritis form. It causes disability in movement that can be defined as patient's need to help for walking or climbing stairs. For patients with affected knees, this disability is more than any other medical condition in the age of 65 [1].

\footnotetext{
* Correspondence: dr.enas2000@gmail.com

${ }^{1}$ Rheumatology and Rehabilitation Department, Faculty of Medicine,

Beni-Suef University, Beni-Suef, Egypt

Full list of author information is available at the end of the article
}

Osteoarthritis is a chronic degenerative joint disease characterized by degraded articular cartilage, damaged subchondral bone, and synovitis. Osteoarthritis causes a significant health problem on communities because it causes limitation in functional activities [2].

Inflammation is considered as a clear pathogenic mechanism for osteoarthritis development and progression that the disease can be regarded as an inflammatory one [3]. Chondrocytes can yield a diversity or inflammatory cytokines. Inflammation has an important role in joints and cartilage loss [4].

\section{Springer Open}

(ㅇ The Author(s). 2021 Open Access This article is licensed under a Creative Commons Attribution 4.0 International License, which permits use, sharing, adaptation, distribution and reproduction in any medium or format, as long as you give appropriate credit to the original author(s) and the source, provide a link to the Creative Commons licence, and indicate if changes were made. The images or other third party material in this article are included in the article's Creative Commons licence, unless indicated otherwise in a credit line to the material. If material is not included in the article's Creative Commons licence and your intended use is not permitted by statutory regulation or exceeds the permitted use, you will need to obtain permission directly from the copyright holder. To view a copy of this licence, visit http://creativecommons.org/licenses/by/4.0/. 
Adrenomedullin is a peptide; its structure includes 52 amino acids and it belongs to the calcitonin/calcitonin gene-related peptide (CGRP) family [5]. It was first recognized in pheochromocytoma of human [6]. Adrenomedullin expression occurs not only in cardiovascular system but also in other tissues as bones and joints. In addition to its strong effect in vasodilation and hypotension, Adrenomedullin also has a role as an antiinflammatory. Adrenomedullin can effectively suppress the activated macrophages and prevent their production of tumor necrosis factor- $\alpha$ (TNF- $\alpha$ ) [7]. Neuropeptides as AM may show strong anti-inflammatory effects. They may control various serious levels of innate immunity [8]. The ability of these neuropeptides to control adaptive immunity has been documented. They can affect activation/differentiation of Th1 cells [9].

Adrenomedullin was found to inhibit interleukin-1induced proliferation of fibroblast-like synoviocytes which contribute to the development of OA [3]. Cytokines were significantly decreased in the joints of mice after treatment with Adrenomedullin [8].

Adrenomedullin was able to eliminate inflammation and lessen systemic loss of bone in collagen induced arthritis in murines. It can be involved in pathogenesis of osteoarthritis through its antiinflammatory effect [10].

The current study was designed to assess serum Adrenomodullin concentrations in patients with knee osteoarthritis (OA) and to detect the association with the severity of the disease.

\section{Methods}

\section{Patients}

This present study was a case-control study conducted on fifty patients (16 males and 34 females) with primary $\mathrm{OA}$ of the knee who were diagnosed according to American College of Rheumatology (ACR) Revised Criteria for Early Diagnosis of Knee Osteoarthritis [11], in addition to twenty healthy control subjects, with no clinical features of KOA, matched in age and sex (3 males and 17 females). Patients with generalized erosive OA, other rheumatological, neurological disease, or cancer were excluded (Fig. 1).

\section{Methods}

All patients were subjected to full history taking, clinical examination, and routine laboratory investigations. Xray knee anteroposterior view on standing in osteoarthritis patients. Blood samples had been collected from patients with OA and healthy controls and were kept for assessing Adrenomodullin in their sera.

The Kellgren and Lawrence classification [12] was used to evaluate the disease severity of knee OA. If either knee was assessed as KL grade $>$ and $=2$, an $\mathrm{OA}$

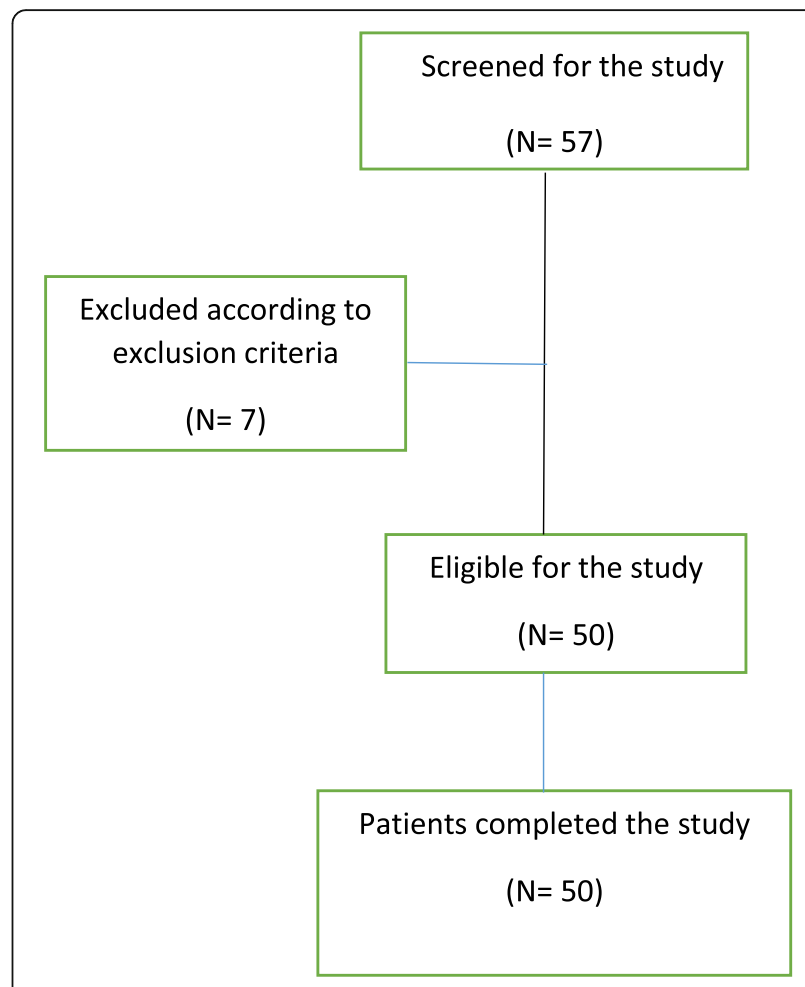

Fig. 1 Flowchart for KOA patients participated in the study

diagnosis was made. Controls were defined as both knee assessed as KL grades of 0 .

Assessment of OA disease activity was done using the Western Ontario and McMaster Universities Arthritis Index (WOMAC).WOMAC is a self-administered questionnaire consisting of 24 items divided into 3 subscales: pain (5 items), stiffness (2 items), and physical function (17 items). The test questions are scored on a scale of 04, which correspond to the following: none (0), mild (1), moderate (2), severe (3), and extreme (4). The scores for each subscale are summed up, with a possible score range of 0-20 for pain, 0-8 for stiffness, and 0-68 for physical function. A sum of the scores for all 3 subscales gives a total WOMAC score [13].

Assessment of pain using visual analog scale (VAS) is a uni-dimensional measure of pain intensity [14].

Concentrations of Adrenomodullin in serum were measured by ELISA technique using commercially available kits according to the manufacturer's instructions (ELISA kit, Cat No EIA-3418, Lot: 601777, DRG International Inc., USA).

\section{Statistical analysis}

The collected data were coded then entered and analyzed using the Statistical Package for Social Sciences (SPSS) computer software (version 25), IBM software, USA. Descriptive statistics was done for categorical variables by frequency and percentage, and for numerical 
variables in the form of mean and standard deviation (mean $\pm \mathrm{SD}$ ).

Suitable statistical tests of significance were used (independent sample $t$ test for two unrelated samples, one way ANOVA test for more than two related samples, and post-hoc (LSD) analysis) to identify which pairs of means were statistically different, chi-square $(\chi 2)$ test for categorical data, Pearson correlation analysis; and ROC (receiver operator characteristic) curve was used to find out the best cut-off value and validity of certain variable. $P$ values equal to or less than 0.05 were considered statistically significant.

\section{Results}

The present case-control study was performed on two matched groups; fifty knee OA patients (case group) distributed as (16) males and (34) females, their ages ranged from 20 to 60 years with a mean of $52.42 \pm 8.76$ years with disease duration ranged from 1 to 20 years with a mean of $6.32 \pm 4.7$ years duration, and 20 healthy individuals (control group) distributed as (3) males and (17) females, their ages ranged from 30 to 60 years with a mean of $50.85 \pm 9.1$ years. Body mass index (BMI) was significantly higher among studied OA cases as compared with healthy control individuals $(33.16 \pm 5.60$ vs. $28.53 \pm 3.71)$ in OA and healthy controls respectively ( $p$ value $=0.001($ Table 1$)$.

All the studied OA cases expressed that they suffer from pain, most studied OA cases expressed suffering from morning stiffness (46 cases out of 50) 92\%, while only half of the OA cases suffered from limping (26 cases out of 50), as reported by the patients. Our patients were on non-steroidal anti-inflammatory drugs on demand and were on chondroprotectives irregularly.

Disease activity as assessed by total WOMAC score in OA patients ranged from 40 to 89 with a mean disease activity score of $65.58 \pm 13.9$. Pain intensity assessment by visual analog scale (VAS) score showed that more than half the studied cases [31] had VAS score $>6(62 \%)$ while 19 cases had VAS score $<6$ (38\%) (Table 1). As regarding KL score, twenty-three cases were grade 2, fifteen cases were grade 3, and twelve cases were grade 4 with no statistically significant differences between right and left side.

There was a statistically significant higher serum Adrenomedullin levels in the KOA patients compared to the control group $(10.64 \pm 19.2$ vs. $1.39 \pm 1.6)$ in cases and controls respectively $(p$ value $=0.036)($ Fig. 2$)$

There were no detected significant difference in serum Adrenomedullin levels among studied OA cases according to their sex $(p$ value $>0.05)$.

Spearman correlation analysis showed a positive significant correlation of serum Adrenomedullin levels with
Table 1 Socio-demographic data and clinical assessment of the studied population $(N=70)$

\begin{tabular}{|c|c|c|c|}
\hline & $\begin{array}{l}\text { Knee OA patients } \\
N=50\end{array}$ & $\begin{array}{l}\text { Healthy controls } \\
N=20\end{array}$ & $p$ value \\
\hline \multicolumn{4}{|l|}{ Sex; $N(\%)$} \\
\hline Male & $16(32.0)$ & $3(15.0)$ & 0.234 \\
\hline Female & $34(68.0)$ & $17(85.0)$ & \\
\hline \multicolumn{4}{|l|}{ Age; (years) } \\
\hline Mean $\pm \mathrm{SD}$ & $52.42 \pm 8.76$ & $50.85 \pm 9.1$ & 0.238 \\
\hline Range & $20-60$ & $30-60$ & \\
\hline \multicolumn{4}{|l|}{ BMI; $\left(k g / m^{2}\right)$} \\
\hline Mean \pm SD & $33.16 \pm 5.60$ & $28.53 \pm 3.71$ & $0.001^{*}$ \\
\hline Range & $22.50-45.00$ & $21.80-33.60$ & \\
\hline \multicolumn{4}{|c|}{ Disease duration; (years) } \\
\hline Mean \pm SD & $6.32 \pm 4.7$ & NA & \\
\hline Range & $1.00-20.00$ & & \\
\hline \multicolumn{4}{|c|}{ WOMAC score } \\
\hline Mean \pm SD & $65.58 \pm 13.9$ & NA & \\
\hline Range & $(40-89)$ & & \\
\hline \multicolumn{4}{|l|}{ VAS; $N(\%)$} \\
\hline$<6$ & $19(38.00 \%)$ & NA & \\
\hline$>6$ & 31 (62.00\%) & & \\
\hline
\end{tabular}

$O A$ osteoarthritis, NA unrelated, $B M I$ body mass index, WOMAC Western Ontario and McMaster Universities Arthritis Index, VAS visual analog scale Comparison between cases and controls was done using chi-square test, unpaired $t$ test, or Mann-Whitney $U$ test, as appropriate

KL grades $(r=0.608, p$ value $<0.001)$ in the OA patients (Fig. 3).

No detected significant correlation between any of patients' age, BMI, disease duration, and disease activity as assessed by WOMAC score with serum Adrenomedullin levels among studied OA cases ( $p$ values $>0.05$ ) (Table 2).

There were significantly higher serum Adrenomedullin levels in the OA case group with VAS score $>6$ as compared to the OA case group with VAS score $<6(14.60 \pm$ 23.5 vs. $4.18 \pm 4.2)$ in VAS score $(>6)$ and $(<6)$ respectively ( $p$ value $=0.022$ ).

As demonstrated in Table 3 and Fig. 4, receiver operating characteristic (ROC) curve analysis was used to assess the clinical diagnostic accuracy of serum AM levels in the studied knee OA patients and the normal individuals; the results of serum AM levels (ROC) curve analysis showed $p$ value $<0.05$, so the serum AM level diagnosed the disease state at a statistically significant level with a $72 \%$ sensitivity (true positive cases) and 65\% specificity (true negative cases) at a cutoff point level $\geq 2.100$.

\section{Discussion}

Adrenomedullin is a truncated peptide with antiapoptotic and immunoregulatory properties. It can act as an 


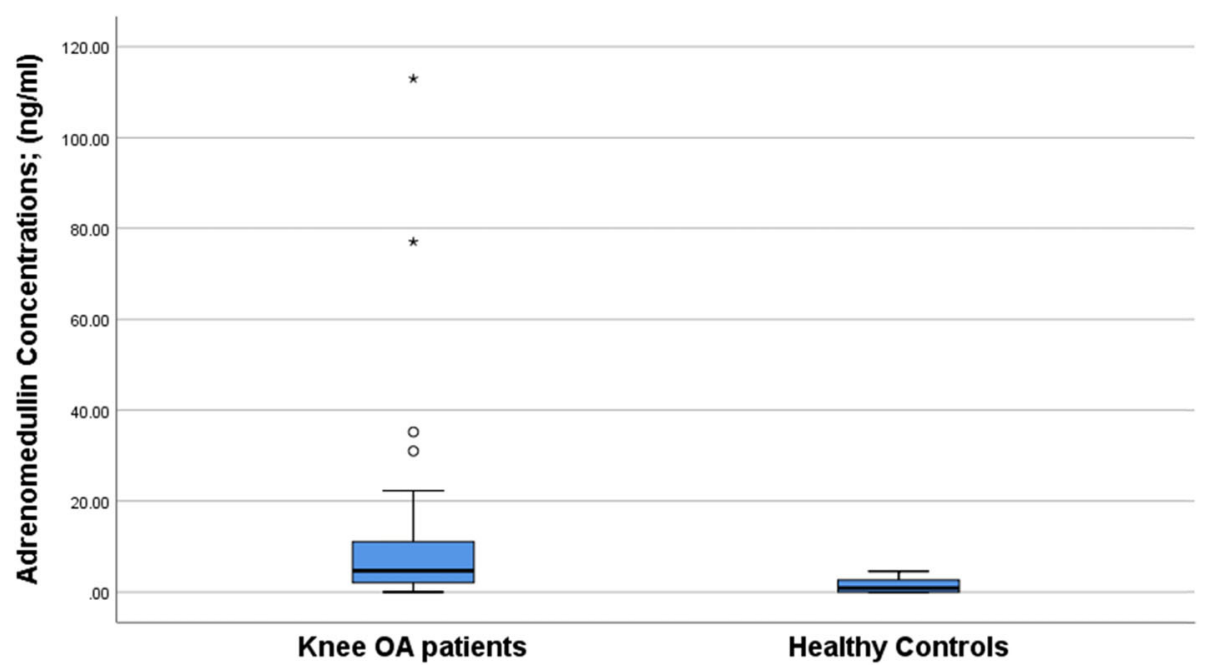

Fig. 2 Serum Adrenomedullin concentrations in the case and control group

agonist or an antagonist depending on cell type. Its in vivo effects are unknown, but Adrenomedullin could possess immunomodulatory properties [15].

Treatment with Adrenomedullin resulted in considerably fewer apoptotic chondrocytes and diminished cartilage degradation in a mouse model of arthritis. After the injection of Adrenomedullin into the knee joint spaces, rabbits with antigen-induced arthritis showed decreased joint swelling [8].

Cytokine expression was studied in mouse joint tissue and serum. In mice with collagen induced arthritis, Adrenomedullin reduced clinical and histologic arthritis scores and shifted the pattern of articular and systemic cytokine expression from Th1 to Th2. Tumor necrosis factor $\alpha$, interleukin-6 (IL-6), and IL-17A levels were significantly decreased in the joints of mice treated with Adrenomedullin, whereas IL-4 and IL-10 levels were increased [15].

Inflammation is involved in the mechanism of OA. Injection with Adrenomedullin in knee joint spaces of rabbits reduced edematous changes and infiltration of inflammatory cells in the synovial tissues. In addition, Adrenomedullin significantly reduced the expression levels of TNF- $\alpha$, IL-6, and IL-17A levels [8].

This study was performed to assess of serum Adrenomodullin (AM) concentrations in patients with knee osteoarthritis (OA) and detect correlation with severity of the disease. Majority of our studied OA patients were

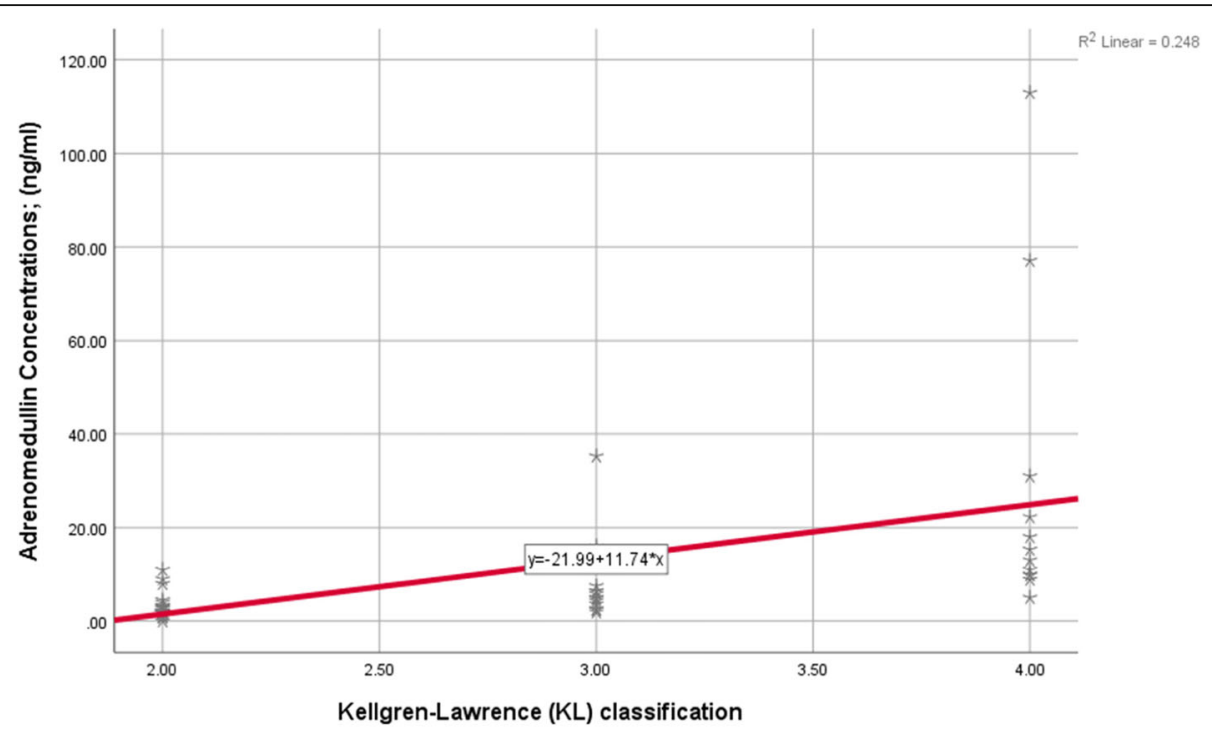

Fig. 3 Correlation between the Kellgren-Lawrence (KL) classification and serum Adrenomedullin concentrations among studied OA cases 
Table 2 Spearman correlation between serum Adrenomedullin concentrations and other parameters of the studied OA cases $(N=50)$

\begin{tabular}{lll}
\hline & \multicolumn{2}{l}{ Adrenomedullin concentrations $(\mathbf{n g} / \mathbf{m l})$} \\
\cline { 2 - 3 } & $\boldsymbol{r}$ & $\boldsymbol{p}$ value \\
\hline Disease duration (years) & -0.035 & 0.812 \\
WOMAC score & 0.217 & 0.130 \\
Age (years) & -0.105 & 0.466 \\
BMl & 0.086 & 0.554 \\
\hline
\end{tabular}

females $(68 \%)$ with a mean age of 52.42 years; this comes in agreement with the mentioned in literature that $\mathrm{OA}$ incidence increases with age and commonly affects females more than males [16].

Although age is intensely related to the development of knee osteoarthritis, overweight is possibly the most significant adjustable risk factor [17]. In harmony with other studies, a strong relation was found in the present study between BMI and knee osteoarthritis, BMI was significantly higher among studied OA cases as compared with healthy control individuals.

In the current study, there was no detected significant correlation between patients age, duration of OA disease with serum Adrenomedullin concentrations in the OA cases.

Body mass index (BMI) has been linked to the prevalence and deterioration of knee osteoarthritis, regardless of age and sex [18]. Even a moderate elevation in BMI was revealed to be significantly associated with knee osteoarthritis [19]. The mechanisms by which obesity is related to the development of knee osteoarthritis are not fully explained. Biomechanical issues (e.g., decreased physical functions and impaired activities, abnormal knee adductor movement, extraordinary burden on the articular cartilage) and metabolic mechanisms (e.g., hormonal dysregulation, liptin) have been proposed as potential facilitating influences for joint osteoarthritis [20].

Higher serum Adrenomedullin levels in the OA group than the control group were detected in the current study with a statistically significant difference. Our findings were in harmony with the reported in similar study implemented in 187 knee OA patients (case group) and 109 healthy subjects (control group) to determine whether serum Adrenomedullin levels were associated with the occurrence and degree of knee osteoarthritis probably as a response to inflammatory cascade; where they reported higher serum

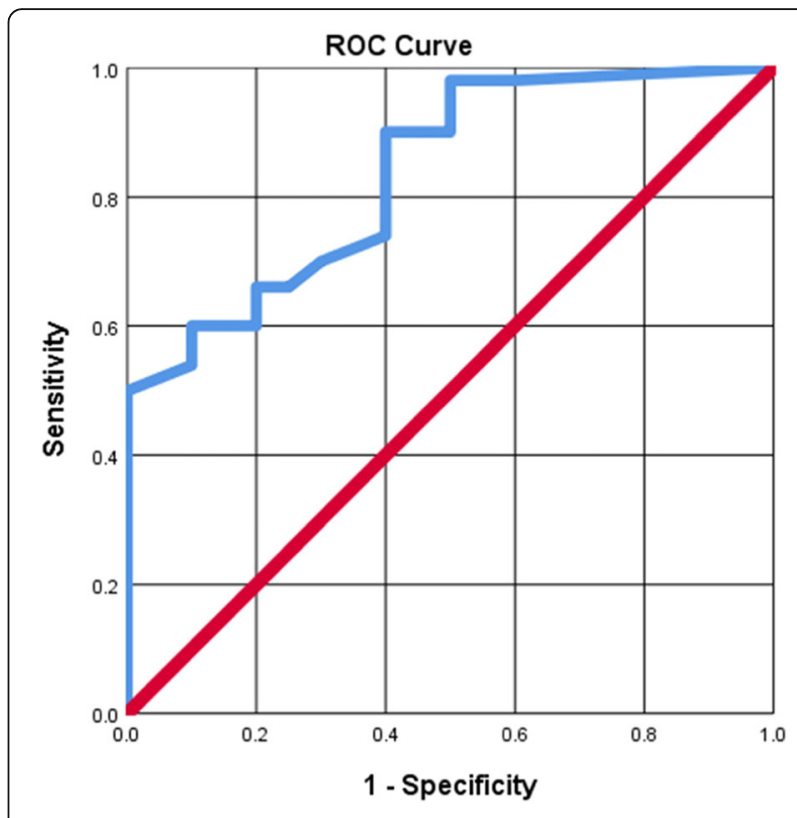

Diagonal segments are produced by ties.

Fig. 4 The results of ROC curve analysis of serum Adrenomedullin concentrations in the studied knee OA patients and normal population

Adrenomedullin levels in the OA group than the control group $(P<0.001)$ [21].

The Kellgren and Lawrence (KL) classification was used to evaluate the disease severity and damage of knee OA. Twenty-three cases were grade 2, fifteen cases were grade 3 , and twelve cases were grade 4 with no statistically significant differences between right and left side. A positive correlation of serum Adrenomedullin concentrations with $\mathrm{KL}$ grades was detected in the present study. This correlation is similar to that reported by Liu and his team in their study; they detected a positive correlation of serum Adrenomedullin concentration with KL grades $(r=0.322, P<0.001)[21]$.

This increase of serum AM level with the increased severity of OA could be explained by the fact that it is secreted in response to inflammation and increased secretion occur with the degree of inflammation.

Serum Adrenomedullin in this study was higher in the OA case group with VAS score $>6$ than the OA case group with VAS score $<6$. It had been found that VAS pain score correlated with Kellgren and Lawrence (KL) classification of disease severity among knee OA [22]; this may explain the statistically significant difference of

Table 3 The results of ROC curve analysis of serum Adrenomedullin concentrations in the studied knee OA patients and normal population

\begin{tabular}{llllllll}
\hline & AUC & SE & $\mathbf{9 5 \%} \mathbf{C l}$ & Sensitivity & Specificity & Cutoff value & $\boldsymbol{p}$ value \\
\hline Adrenomedullin & 0.835 & 0.050 & $0.737-0.933$ & $72 \%$ & $65 \%$ & $\geq 2.100$ & $<0.001$ \\
\hline
\end{tabular}


serum Adrenomedullin concentrations in the OA patients in relation to the VAS score.

The results of our study point to the probability of AM participation in the pathophysiology of joint injuries in patients with OA probably by a combined pro-inflammatory and anti-inflammatory effect. In addition to the fact that AM is recognized to decrease the excretion of cytokines from several cells [23], these results confirm the hypothesis that production of AM in joints and its elevation in the plasma are significantly associated with anti-inflammation in arthritis. Clementi et al. investigated the anti-inflammatory effect of AM in rats, finding that AM production in several cell lines was strongly induced by stimulation of a group of inflammatory cytokines including interleukin 1 and tumor necrosis factor- $\alpha$ [24]. Some studies stated that AM functioned as a circulating vasoactive hormone in blood and plays an anti-inflammatory role in the inhibition of local infection and inflammation, thus playing an important role as a host defense system [25]. Cytokines were significantly decreased in the joints of mice after treatment with Adrenomedullin [8].

Adrenomedullin was found to be elevated in other rheumatic diseases as systemic lupus erythematosus (SLE). El-Srogy et al. detected elevation in serum AM in SLE especially in lupus nephritis patients. AM serum levels were correlated with disease activity in SLE patients. It was negatively correlated with $24 \mathrm{~h}$ urine protein excretion in the group of lupus nephritis patients. Serum AM could be considered a biological marker in SLE [26].

In the current study, the serum AM level diagnosed the disease state at a statistically significant level with a $72 \%$ sensitivity (true positive cases) and $65 \%$ specificity (true negative cases) at a cutoff point level $\geq 2.100$. Unfortunately, we were not able to find similar studies that calculated the sensitivity and specificity of AM in the diagnosis of knee OA to compare them with the results of the current study. However, these results may imply that the serum AM level may be an independent biomarker for identification of severity of knee OA among patients.

The current study has its limitations presented as the small sample size and that patients and control are not matched as regard BMI. Also, we did not measure AM level in synovial fluid for financial reasons. Future studies are needed to determine serum and synovial fluid $\mathrm{AM}$ to determine if the $\mathrm{AM}$ is locally produced in the $\mathrm{OA}$ joints and if it is related to synovitis and effusion in order to discuss AM potential use for treatment of OA.

\section{Conclusion}

Our results propose that plasma AM levels increase with the severity of OA and could be used as a biomarker to detect degree of disease severity. It might have a role in the treatment of OA due to its anti-inflammatory effects, and its plasma levels could be used as a marker of the degree of OA disease. Our findings need to be supported by additional longitudinal studies with larger sample sizes to detect AM concentrations in both serum and synovial fluid in patients with KOA.

\begin{abstract}
Abbreviations
AM: Adrenomedullin; KOA: Knee osteoarthritis; ACR: American College of Rheumatology; WOMAC: The Western Ontario and McMaster Universities Arthritis Index; K/L: Kellgren and Lawrence classification; VAS: Visual analog scale
\end{abstract}

\section{Acknowledgements}

To all the patients and control.

\section{Authors' contributions}

$A B$ collected the data from the patients and control, performed the examination, and was involved in writing the manuscript. EA is the corresponding author and was involved in analyzing the data and writing the manuscript. Ml participated in assessing the patients and writing the manuscript. RA performed the laboratory investigations mainly Adrenomedullin. All authors have read and approved the manuscript.

\section{Funding}

The study had no funding from any resource.

Availability of data and materials

The datasets used and/or analyzed during the current study are available from the corresponding author on reasonable request.

\section{Declarations}

Ethics approval and consent to participate

Verbal/written consents were obtained from the patients and from controls, and were approved by the ethical committee of Faculty of Medicine, BeniSuef University. The reference number is FMBSUREC/05032019/Saed.

Consent for publication

Not applicable.

Competing interests

The authors declare that they have no competing interests.

\section{Author details}

${ }^{1}$ Rheumatology and Rehabilitation Department, Faculty of Medicine, Beni-Suef University, Beni-Suef, Egypt. ${ }^{2}$ Rheumatology and Rehabilitation Department, Beni-Suef General Hospital, Beni-Suef, Egypt. ${ }^{3}$ Clinical Pathology Department, Faculty of Medicine, Beni-Suef University, Beni-Suef, Egypt.

Received: 26 February 2021 Accepted: 30 March 2021

Published online: 16 April 2021

\section{References}

1. Guérard O, Dufort S, Besnard LF, Gougeon A, Carlesso L (2020) Comparing the association of widespread pain, multi-joint pain and low back pain with measures of pain sensitization and function in people with knee osteoarthritis. Clin Rheumatol 39(3):873-879. https://doi.org/10.1007/s10067019-04828-3

2. Musumeci G, Aiello FC, Szychlinska MA (2015) Osteoarthritis in the XXlst century: risk factors and behaviours that influence disease onset and progression. Int J Mol Sci 16(12):6093-6112. https://doi.org/10.3390/ijms16036093

3. Lee EG, Lee SI, Chae HJ (2011) Adrenomedullin inhibits IL-1ß-induced rheumatoid synovial fibroblast proliferation and MMPs, COX-2 and PGE2 production. Inflammation 34(5):335-343. https://doi.org/10.1007/s10753-010-9239-7

4. Ni Z, Zhou S, Li S, Kuang L, Chen H, Luo X et al (2020) Exosomes: roles and therapeutic potential in osteoarthritis. Bone Res 8(1):1-18

5. Takahashi K, Hirose T, Mori N, Morimoto R, Kohzuki M, Imai Y (2009) The renninangiotensin system, adrenomedullins and urotensin in the kidney: possible renoprotection via the kidney peptide systems. Peptides 30:1575-1585 
6. Velard F, Chatron-Colliet A, Côme D, Ah-Kioon MD, Lin H, Hafsia N et al (2020) Adrenomedullin and truncated peptide adrenomedullin affect chondrocyte response to apoptotis in vitro: downregulation of FAS protects chondrocyte from cell death. Sci Rep 10(1):1-12

7. Chosa E, Hamada H, Ohkura T (2012) Role of adrenomedullin in patients with rheumatoid arthritis. Rheumatoid Arthr Treatm 173. https://doi.org/10. $5772 / 25700$

8. Okura T, Marutsuka K, Hamada H, Sekimoto T, Fukushima T, Asada Y, Kitamura K, Chosa E (2008) Therapeutic efficacy of intra-articular adrenomedullin injection in antigen-induced arthritis in rabbits. Arthr Res Ther 10(6):R133. https://doi.org/10.1186/ar2550

9. Chorny A, Delgado M (2008) Neuropeptides rescue mice from lethal sepsis by down-regulating the excretion of the late-acting inflammatory mediator high mobility group box 1. Am J Pathol 172:1297-1307

10. Delgado M, Ganea D (2008) Anti-inflammatory neuropeptides: a new class of endogenous immunoregulatory agents. Brain Behav Immun 22(8):1146-1151

11. Salehi-Abari (2016) 2016 ACR revised criteria for early diagnosis of giant cell (temporal) arteritis. Autoimmune Dis Ther Approaches 3:1

12. Kellgren JH, Lawrence JS (1957) Radiological assessment of osteo-arthrosis. Ann Rheum Dis 16(4):494

13. McConnell S, Kolopack P, Davis AM (2001) The Western Ontario and McMaster universities osteoarthritis index (WOMAC): a review of its utility and measurement properties. Arthritis Rheum 45(5):453-461. https://doi. org/10.1002/1529-0131(200110)45:5<453::AID-ART365>3.0.CO;2-W

14. Bird ML, Callisaya ML, Cannell J, Gibbons T, Smith ST, Ahuja KD (2016) Accuracy, validity, and reliability of an electronic visual analog scale for pain on a touch screen tablet in healthy older adults: a clinical trial. Interact $J$ Med Res 5(1):e3

15. Ah Kioon MD, Asensio C, Ea HK, Velard F, Uzan B, Rulle S et al (2012) Adrenomedullin (22-52) combats inflammation and prevents systemic bone loss in murine collagen-induced arthritis. Arthritis Rheum 64(4):1069-1081. https://doi.org/10.1002/art.33426

16. Pal CP, Singh P, Chaturvedi S, Pruthi KK, Vij A (2016) Epidemiology of knee osteoarthritis in India and related factors. Indian J Orthopaed 50(5):518

17. Ali MT (2018) Risk factor for knee osteoarthritis among women. Mosul J Nurs 6(2):98-103. https://doi.org/10.33899/mjn.2018.163004

18. Eaton CB, Sayeed M, Ameernaz S, Roberts MB, Maynard JD, Driban JB et al (2017) Sex differences in the association of skin advanced glycation endproducts with knee osteoarthritis progression. Arthr Res Ther 19(1):36

19. Di Maio S, Keller J, Job V, Felsenberg D, Ertel W, Schwarzer R et al (2020) Health demands moderate the link between willpower beliefs and physical activity in patients with knee osteoarthritis. Int J Behavior Med 27(4):406414. https://doi.org/10.1007/s12529-020-09865-w

20. Messier SP, Beavers DP, Mihalko SL, Miller GD, Lyles MF, Hunter DJ et al (2020) The effects of intensive dietary weight loss and exercise on gait in overweight and obese adults with knee osteoarthritis. The intensive diet and exercise for arthritis (IDEA) trial. J Biomech 98:109477

21. Liu L, Huang R, Ma D, Cheng W, Feng W, Xing D, Kan W, Xiao Z (2016) Correlation of adrenomedullin concentrations with knee osteoarthritis grade. Med Sci Monitor 22:2775-2778. https://doi.org/10.12659/MSM.896987

22. Holzer N, Salvo D, Marijnissen ACA, Vincken KL, Ahmad AC, Serra E et al (2015) Radiographic evaluation of posttraumatic osteoarthritis of the ankle: the Kellgren-Lawrence scale is reliable and correlates with clinical symptoms. Osteoarthr Cartil 23(3):363-369. https://doi.org/10.1016/.joca.2014.11.010

23. Patel P, Mishra A, Sheikh AA, Kumar K, Bhagat R, Maibam U (2017) Adrenomedullin: a novel peptide hormone: a review. J Pharmacogn Phytochem 6(6):2068-2073

24. Clementi G, Caruso A, Cutuli VMC, Prato A, de Bernardis E, Fiore CE et al (1995) Anti-inflammatory activity of amylin and CGRP in different experimental models of inflammation. Life Sci 57(14):193-197

25. Takano S, Uchida K, Miyagi M, Inoue G, Aikawa J, Iwabuchi K, Takaso M (2017) Adrenomedullin regulates IL-1 $\beta$ gene expression in F4/80. J Immunol Res 2017:1-10. https://doi.org/10.1155/2017/9832430

26. El-serougy E, Ahmed HH, Kamal MM, Niazy MH (2015) The neuropeptide adrenomedullin, could it be linked to renal involvement and disease activity in systemic lupus erythematosus? Egypt Rheumatol 37(2):19-24

\section{Publisher's Note}

Springer Nature remains neutral with regard to jurisdictional claims in published maps and institutional affiliations.

\section{Submit your manuscript to a SpringerOpen ${ }^{\circ}$ journal and benefit from:}

- Convenient online submission

- Rigorous peer review

- Open access: articles freely available online

- High visibility within the field

- Retaining the copyright to your article

Submit your next manuscript at $\boldsymbol{\nabla}$ springeropen.com 